(RESEARCH ARTICLE)

\title{
Effect of high density planting on the vigour and yield of Theobroma cacao L. in the Southwest of Nigeria
}

Ayegboyin Kayode Olufemi *, Famaye Amos Olatunde, Adeosun Seun Adewale, Idrisu Mohammed, Ugioro Osasogie, Asowata Frank Efe and Okunade Favour Adeyemi

Cocoa Research Institute of Nigeria, KM 14, Ibadan - Ijebu-Ode Road, Idi-Ayunre, PMB 5422, Ibadan, Nigeria.

Publication history: Received on 14 June 2020; revised on 27 September 2020; accepted on 29 September 2020

Article DOI: https://doi.org/10.30574/wjarr.2020.8.1.0203

\begin{abstract}
Cocoa was established at Owena in the Southwestern part of Nigeria using four planting distances of $3.0 \times 3.0 \mathrm{~m}, 2.5 \mathrm{x}$ $2.5 \mathrm{~m}, 2.0 \times 2.0 \mathrm{~m}$ and $1.5 \times 1.5 \mathrm{~m}$ which was laid out in a Complete Randomized Block Design with four replicates. Data was collected between August 2014 and May 2017 on the survival count, morphological parameters (plant height, stem circumference and number of branches), number of cocoa pods and dry cocoa beans weight to determine the vigour and yield performance of cocoa plants. The results revealed significant differences $(\mathrm{p}=0.05)$ between treatments based on the plant spacing. While cocoa plants on $3.0 \times 3.0 \mathrm{~m}$ treatment had significantly higher height, stem circumference and number of branches than those on $2.0 \times 2.0 \mathrm{~m}$ and $1.5 \times 1.5 \mathrm{~m}$ from 12 months after transplanting. The number of cocoa pods and weight of dry cocoa beans for individual cocoa trees followed the same trend with their vigour performance. However, the total yield per hectare showed significantly higher value $(p=0.05)$ for cocoa under close spacing than the recommended traditional $3.0 \times 3.0 \mathrm{~m}$ with low population density planting. With the present results, we recommend that cocoa farmers in Nigeria should explore a high planting density system during the first few years of establishment while the trees surpluses should be eliminated once the plants' canopy spread are becoming too interwoven.
\end{abstract}

Keywords: Cocoa; Establishment; Spacing; Vigour; Yield

\section{Introduction}

The optimum planting distance of cocoa is the planting density that gives the highest economic return per unit area of land. Each country has adopted a certain spacing which has become more or less traditional. For instance, the original spacing was 5.0 × 5.0 m in Samoa and Papua New Guinea, 4.0 × 4.0 m in Trinidad and Dominican Republic and 3.0 x 4.0 $\mathrm{m}$ in the South America [18]. In West African countries like Nigeria, Ghana and Cote D'Iviore much smaller planting distance of $3.0 \times 3.0 \mathrm{~m}$ and $2.5 \times 2.5 \mathrm{~m}$ are adopted. According to Wood and Lass [18], West Africa is the only cocoa growing region where a very close spacing is used. In Nigeria, low density planting with many permanent overhead shades, inadequate levels of pruning and the use of little or no of fertilisers which are characterisations of low tree productivity have been in existence since 1970s.

Nigeria is currently the fifth largest cocoa producer in the world [8] while cocoa is one of the main agricultural produce in the southwest of Nigeria especially when the size of areas of production and number of farmers involved in its cultivation in this region are taken into consideration [1]. Through provision of good yield and sustainable economic benefits, cocoa cultivation constitutes an important basis for the support of many indigenous families in the southwest of Nigeria. The local industry in the region comprises of far above 10 million farmers with each of these farmers operating on less than 10 ha farm size although, many commercial farmers with more than 20 ha of good productive

\footnotetext{
${ }^{*}$ Corresponding author: Ayegboyin Kayode Olufemi

Cocoa Research Institute of Nigeria, KM 14, Ibadan - Ijebu-Ode Road, Idi-Ayunre, PMB 5422, Ibadan, Nigeria..
} 
cocoa farms are also present in the area. Smallholders cocoa plantation in Nigeria often favour companion cropping of plantain/banana as well as some fruit species and use of little or no fertilisers [1]. Most of these smallholder farmers in southwest of Nigeria commonly use CRIN recommended low density planting (LDP) of cocoa of $3.0 \times 3.0 \mathrm{~m}$ spacing while some educated commercial farmers adopt $2.5 \times 2.5 \mathrm{~m}$ spacing and grow their cocoa as a monocrop. Plantain and/or banana are traditionally planted as nurse crops for cocoa during the early years of establishment but a few economic crops like kola, orange and oil palm are sometimes intercropped with cocoa. However, some economic trees like pear, African star apple, Irvingia ganbonensis as well as a few non-economic trees are also allowed to grow along with cocoa plants to provide shade as well as an avenue for an additional revenue on the farms. While productivity of a smallholder farm ranges from 250 to $400 \mathrm{~kg} \mathrm{ha}^{-1}$, on the larger modern farms where higher inputs are used, yield ranges between 400 and $700 \mathrm{~kg} \mathrm{ha}^{-1}$. Such yield also depends on the variety planted as well as the management of the farm as farmers sometimes would not accurately use inorganic fungicides and end up in loss of yield that could be as high as $40 \%$ to black pod disease [14].

Several trials had been conducted in other countries to demonstrate the superiority of high density population over the traditional low density plantings. Gutierrez [5] reported a direct linear positive relationship between higher yield per unit land area under high density planting (HDP) in Colombia while [17] reported a rise per hectare in the dry bean weight of cocoa from plantations established with a HDP technique in Malaysia and [12] established a better yield performance per hectare of cocoa under HPD in Trinidad and Tobago.

In Nigeria, after several spacing trials in the Seventies, three planting distances of $2.5 \times 2.5 \mathrm{~m}, 3.0 \times 3.0 \mathrm{~m}$ as well as the $3.1 \times 3.1 \mathrm{~m}$ which was translated directly from the old 10 feet $\times 10$ feet spacing were all recommended for cocoa establishment by the Cocoa Research Institute of Nigeria (CRIN), Ibadan. However, due to the difficulty encountered by farmers whenever $3.1 \times 3.1 \mathrm{~m}$ (10 x 10 feet) spacing was adopted, CRIN eventually reduced recommended spacing of cocoa to $2.5 \times 2.5 \mathrm{~m}$ and $3.0 \times 3.0 \mathrm{~m}$ resulting in 1600 and 1111 trees ha ${ }^{-1}$, respectively. However, research effort that will ensure cocoa sustainable production at the early stage of establishment are seen as a step in the right direction which remains sacrosanct for the survival of young cocoa in the field and the improvement of farmers' income [1]. Obviously, with the arrival of several developmental projects, rural-urban labour shift and competition for arable land for farming in southwest of Nigeria, it is obvious that a consented effort for effective resource use and increase productivity in cocoa farming must be adopted. The future of cocoa in the southwest of Nigeria will depend more on the optimisation of cocoa yield per unit area of land rather than acquisition of large space of land for cultivation which calls for research and adoption of the HDP strategy for cocoa production in the country [12]. This experiment was set out to determine the highest population density at which cocoa trees could be effectively planted to give the greatest economic returns per hectare in the South-western part of Nigeria.

\section{Material and methods}

The experiment was established in 2014 at Cocoa Research Institute of Nigeria, Owena, Ondo State with longitude $7.1961^{\circ} \mathrm{N}$, latitude $5.0195^{\circ} \mathrm{E}$ in the forest zone of southwest of Nigeria. The specimen cocoa seedlings were raised for 6 months in the nursery and transplanted at the outset of raining season in May, 2014 from pods of clones TC $_{1-8}$ Series of Upper Amazonian breeds which are popularly called 18-month cocoa.

Four different planting distances of $3.0 \times 3.0 \mathrm{~m}, 2.5 \times 2.5 \mathrm{~m}, 2.0 \times 2.0 \mathrm{~m}$ and $1.5 \times 1.5 \mathrm{~m}$ with plant population densities of $1111 \mathrm{ha}^{-1}, 1600 \mathrm{ha}^{-1}, 2,500 \mathrm{ha}^{-1}$, and $4445 \mathrm{ha}^{-1}$ respectively, were used in establishing the experimental plots while 49 stands of cocoa were planted as a treatment. The experiment was laid out in a Completely Randomized Block Design with 4 replications resulting into 784 total number of cocoa trees in the experiment. As a research criterion which was recommended by CRIN, plantain (Musa spp.) suckers were established in-between cocoa stands as a nurse crop to form a temporary shade for the young cocoa trees during the first 2 dry seasons of establishment. Also, some tall forest trees which were already on the field before field clearing were left to form some kind of permanent shade to complement the temporary shade from the nurse crop. Supplies of missing gaps were done with cocoa plants from the same old stock of seedlings used for establishing the field to ensure uniformity of age of cocoa trees.

Data was collected at a 3-month interval on the randomly selected 320 cocoa trees (i.e. 20 stands per treatment per replication) on the plant height, stem circumference, number of branches, number of cocoa pods and weight of dry cocoa beans to determine the vigour and yield of each tree. The plant height, stem circumference and number of branches were used to determine the vigour or morphological growth parameters of cocoa trees. While all visible cocoa podsplus cherelle were counted and referred to as 'pods produced per time', the weight of dry cocoa beans, which was dried to $8 \%$ moisture content before weighing. The effects of plant population density on the measured parameters were tested by means of analysis of variance (ANOVA) using Genstat $13^{\text {th }}$ edition (VSN International Limited) while the significant differences between treatment means were determined by the least significant difference (LSD) at $p=0.05$. For time 
series data two-way ANOVA was conducted for each time point. Relationships between the plant population density and cocoa yield (number of pods produced and weight of dry cocoa beans) parameters were determined by means of linear regression in Excel 2013 edition,

\section{Results and discussion}

\subsection{Survival count}

The results of the survival count done between 3 and 12 WAT showed that cocoa trees planted at $1.5 \times 1.5 \mathrm{~m}$ and $3.0 \mathrm{x}$ $3.0 \mathrm{~m}$ had the highest and lowest value of $86.8 \%$ and $83.5 \%$, respectively at 12WAT (Fig. 1), yet there were no significant differences in the survival rates among all treatments during any particular period of data collection. Invariably, all cocoa trees that survived and physically counted at 12 WAT (weeks after transplanting) remained alive and productive till 36 MAT (months after transplanting) when the data collection was completed.

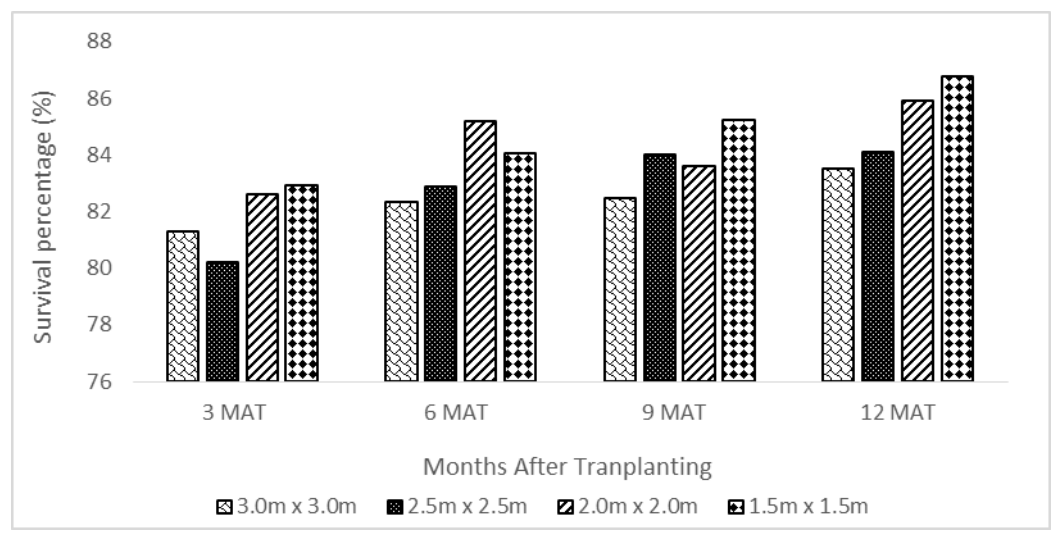

Figure 1 Survival count (\%) of the cocoa trees between 3WAT and 12 WAT

\subsection{Plant height}

Cocoa planted at $3.0 \times 3.0$ m performed better than other planting distances while the crops on $1.5 \times 1.5 \mathrm{~m}$ were the shortest for most of the period of data collection. The results also showed significant differences in the height of cocoa plants between treatments especially from 21 MAT, except at 27 MAT when the mean height of cocoa at $2.5 \times 2.5 \mathrm{~m}$ was the shortest (Table 1).

Table 1 Mean of plant height (cm) of cocoa under different planting distances

\begin{tabular}{|l|l|l|l|l|l|}
\hline Month After Transplanting (MAT) & $\mathbf{3 . 0} \mathbf{3 . 0} \mathbf{~ m}$ & $\mathbf{2 . 5} \mathbf{2 . 5} \mathbf{~ m}$ & $\mathbf{2 . 0} \mathbf{2 . 0} \mathbf{~ m}$ & $\mathbf{1 . 5} \mathbf{~ 1 . 5} \mathbf{~ m}$ & $\mathbf{p = 0 . 0 5}$ \\
\hline 3 MAT & 33.03 & 32.20 & 32.27 & 32.90 & 0.91 \\
\hline 6 MAT & 45.54 & 45.27 & 44.75 & 45.58 & 0.94 \\
\hline 9 MAT & 52.51 & 52.67 & 52.61 & 53.08 & 0.62 \\
\hline 12 MAT & 60.96 & 60.71 & 61.39 & 61.53 & 0.93 \\
\hline 15 MAT & 72.94 & 73.13 & 72.51 & 72.93 & 0.84 \\
\hline 18 MAT & 83.57 & 83.00 & 82.74 & 82.71 & 0.84 \\
\hline 21 MAT & 87.93 & 87.64 & 88.81 & 89.62 & $1.25^{* * *}$ \\
\hline 24 MAT & 95.93 & 96.95 & 94.99 & 94.71 & $1.85^{* * *}$ \\
\hline 27 MAT & 106.03 & 105.02 & 105.76 & 105.37 & $1.25^{* * *}$ \\
\hline 30 MAT & 110.43 & 109.46 & 111.54 & 115.18 & $1.10^{* * *}$ \\
\hline 33 MAT & 120.93 & 120.37 & 119.23 & 118.88 & $1.85^{* * *}$ \\
\hline 36 MAT & 130.97 & 130.60 & 128.42 & 127.20 & $2.91^{* * *}$ \\
\hline
\end{tabular}


Legend: ${ }^{* * *}$ statistical significant different

\subsection{Stem circumference}

Similar to plant height, cocoa planted at $3.0 \times 3.0 \mathrm{~m}$ spacing had bigger stem circumferences than those under higher plant population densities of $1.5 \times 1.5 \mathrm{~m}$ and $2.0 \times 2.0 \mathrm{~m}$ with differences in the thickness of these cocoa plants between the treatments becoming significant from 24 MAT with exception at 12 MAT (Tab. 2). The experiment also revealed presence of a reverse relationship between increase planting population densities and higher values of cocoa stem thickness.

Table 2 Mean of stem circumference ( $\mathrm{mm}$ ) of cocoa under different planting distances

\begin{tabular}{|l|l|l|l|l|l|}
\hline Month After Transplanting (MAT) & $\mathbf{3 . 0} \mathbf{x . 0} \mathbf{~ m}$ & $\mathbf{2 . 5} \mathbf{2} \mathbf{2 . 5} \mathbf{~ m}$ & $\mathbf{2 . 0} \mathbf{2} \mathbf{2 . 0} \mathbf{~ m}$ & $\mathbf{1 . 5} \mathbf{x} \mathbf{1 . 5} \mathbf{~ m}$ & $\mathbf{p = 0 . 0 5}$ \\
\hline 3 MAT & 9.54 & 9.41 & 10.01 & 9.57 & 0.63 \\
\hline 6 MAT & 15.51 & 14.95 & 15.70 & 14.85 & 1.69 \\
\hline 9 MAT & 20.05 & 19.46 & 19.93 & 20.12 & 1.67 \\
\hline 12 MAT & 28.05 & 26.79 & 27.30 & 27.51 & $0.71^{* * *}$ \\
\hline 15 MAT & 37.46 & 36.11 & 36.35 & 36.15 & 1.35 \\
\hline 18 MAT & 43.75 & 42.80 & 43.32 & 42.27 & 1.55 \\
\hline 21 MAT & 57.74 & 58.07 & 57.83 & 56.90 & 1.18 \\
\hline 24 MAT & 69.89 & 69.79 & 69.79 & 69.00 & $0.87^{* * *}$ \\
\hline 27 MAT & 82.01 & 81.99 & 81.65 & 79.88 & $0.98^{* * *}$ \\
\hline 30 MAT & 96.24 & 96.15 & 95.54 & 95.16 & $1.03^{* * *}$ \\
\hline 33 MAT & 101.63 & 101.30 & 101.22 & 100.60 & $1.01^{* * *}$ \\
\hline 36 MAT & 128.53 & 127.93 & 127.20 & 127.21 & $1.09^{* * *}$ \\
\hline
\end{tabular}

\subsection{Number of branches}

Although, the plants did not produce any branch until around 6 MAT, performance of all cocoa plants were not statistically different from one another until around 24 MAT. The number of branches increase with lower planting population with plants at $1.5 \times 1.5 \mathrm{~m}$ and $2.0 \times 2.0 \mathrm{~m}$ were significantly lower than those on $2.5 \times 2.5 \mathrm{~m}$ and $3.0 \times 3.0 \mathrm{~m}$ at 30, 33 and as well as 36 MAT (Tab. 3)

Table 3 Mean of number of branches of cocoa under different planting distances

\begin{tabular}{|c|c|c|c|c|c|}
\hline Month After Transplanting (MAT) & $3.0 \times 3.0 \mathrm{~m}$ & $2.5 \times 2.5 \mathrm{~m}$ & $2.0 \times 2.0 \mathrm{~m}$ & $1.5 \times 1.5 \mathrm{~m}$ & $p=0.05$ \\
\hline 3 MAT & 0.00 & 0.00 & 0.00 & 0.00 & - \\
\hline $6 \mathrm{MAT}$ & 3.64 & 3.08 & 3.00 & 3.05 & 0.45 \\
\hline 9 MAT & 6.90 & 7.33 & 6.65 & 6.07 & 1.45 \\
\hline 12 MAT & 10.65 & 10.93 & 10.00 & 9.23 & 1.82 \\
\hline 15 MAT & 17.64 & 18.01 & 16.50 & 16.50 & 1.55 \\
\hline 18 MAT & 21.51 & 21.29 & 20.23 & 21.07 & 1.30 \\
\hline $21 \mathrm{MAT}$ & 29.44 & 28.73 & 28.38 & 28.36 & 1.11 \\
\hline 24 MAT & 35.29 & 34.99 & 33.90 & 33.76 & $1.30^{* * *}$ \\
\hline 27 MAT & 39.04 & 38.93 & 40.32 & 40.02 & $1.21^{* * *}$ \\
\hline 30 MAT & 40.41 & 40.40 & 41.05 & 40.11 & $1.00^{* * *}$ \\
\hline 33 MAT & 46.32 & 47.30 & 44.20 & 44.81 & $2.01^{* * *}$ \\
\hline 36 MAT & 53.23 & 52.02 & 49.14 & 49.90 & $2.20^{* * *}$ \\
\hline
\end{tabular}


Legend: *** statistical significant different

\subsection{Cocoa pods and dry beans production at different planting distances}

Cocoa pods and dry beans weight for individual tree showed that individual yield performance increased with larger planting spacing (Fig. 2), Individual cocoa yield production under $3.0 \times 3.0 \mathrm{~m}$ spacing became significantly higher than those at $1.5 \times 1.5 \mathrm{~m}$ and $2.0 \times 2.0 \mathrm{~m}$ between 30 and 36 MAT. However, the total number of pods and dry beans weight produced per hectare at 36 WAT showed that cocoa planted at $1.5 \times 1.5 \mathrm{~m}$ had the highest values of pods and dry beans weight (Fig. 3).

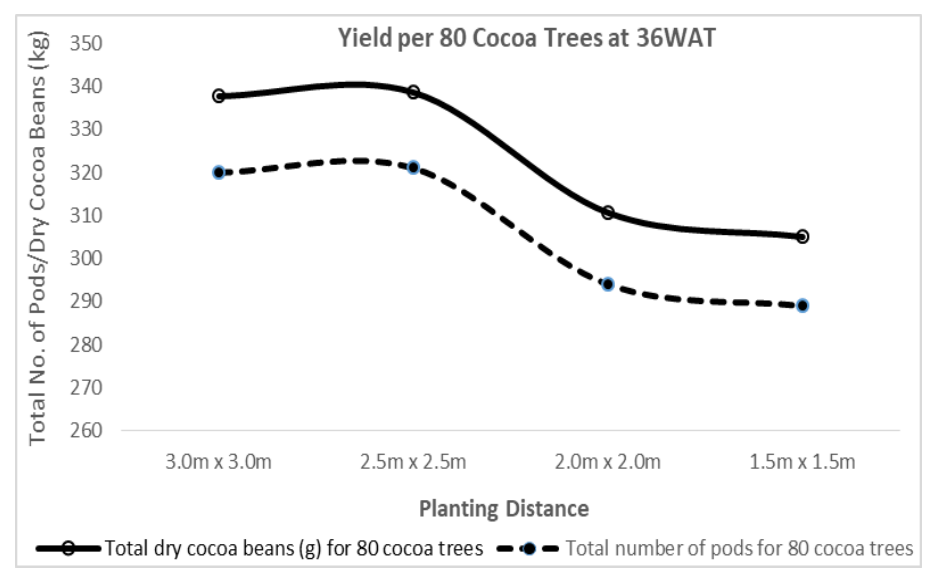

Figure 2 Number of cocoa pods and weight (g) of cocoa beans at $8 \%$ moisture content produced by 80 cocoa trees at 36 weeks after transplanting

\section{Discussion}

\subsection{Survival and vigour of cocoa plant}

The results showed that the survival of the transplanted cocoa plants did not depend on the spacing adopted during the experiment. This could be because the interaction among the young cocoa plants did not affect their growth and development at the very early stage of field establishment. Also, the varied values of plant height, stem circumference and number of branches, which progressively increased with time and wider planting distances, revealed that the morphology of cocoa plants improved with age and space. This discovery is in consonant with the reports of [6] that due to the competition that exists among them, closely spaced cocoa seedlings produced a smaller number of leaves and other morphological parameters than well-spaced ones. Wilson [14] as well as Famuwagun and Agele [7] also established that the height, stem circumference and number of leaves of plants are among the main factors that determined the vigour needed for the survival and growth of cocoa seedlings after transplanting. Therefore, the trial confirmed a direct relationship between the strong vigour and the lower planting distance of cocoa plants, especially with recommended spacing of $3.0 \times 3.0 \mathrm{~m}$ and $2.5 \times 2.5 \mathrm{~m}$ for cocoa farms in the southwest of Nigeria being in the focus.

\subsection{Plant yield}

Cocoa performance showed that conventional planting spacing of $3.0 \times 3.0 \mathrm{~m}$ which is LDP, had significantly higher number of cocoa pods and more dry cocoa beans weight for individual tree performance than those under HDP of $2.0 \mathrm{x}$ $2.0 \mathrm{~m}$ and $1.5 \times 1.5 \mathrm{~m}$. Also, the production of cocoa trees showed that cumulative yield per ha under HDP had superior yield values than those under LDP since plant population is one of the main reasons for greater yield of cocoa trees per unit area of land under HDP. Mooleedhar [12] obtained similar results of significantly higher yields from cocoa planted under close spacing than those from the intermediate and traditional spacing. Apart from higher cumulative yield per ha, availability of more cocoa stands per unit area of land under HDP provides an avenue for earlier overlapping of cocoa trees and canopy closure that encourages many conditions desirable for optimal plant growth and the eventual better yield per unit area of land. It has been established that HPD also encourages a greater relative number of surviving productive trees over a period of time which provides a better plant environment for early cocoa growth and development [13]. This is because while missing trees with their potential reduction in total economic yield are frequently observed under LDP, vigorous adjacent trees under HDP easily fill the open spaces caused by either poor performing trees or the missing stands observed during the early establishment phase of cocoa fields [12]. 


\subsection{Cocoa variety and farm management in HDP}

The present study shows that although the total number of cocoa pod and weight of dry cocoa beans per ha directly increased with time, individual tree yield performance and time were inversely related under HDP (Fig. 2). This finding is similar to the reports by [9] and [2] where the yields per plant in HDP were much lower over a long period of time than their counterparts in LDP. Souza et al., [15] established that continued HDP might not be a highly productive venture throughout the lifespan of cocoa plantation while [11] confirmed that yields of a vigorous cocoa variety might not be sustainable beyond the first ten years of production without a good manipulation of vegetative growth through pruning and other good agricultural practices that will ensure good plant health. One explanation is that as cocoa plantation grow, there is a lower interplant competition between trees under LDP than HDP which invariably favours better growth and higher pod production for individual trees under LDP, especially when vigorous variety is used. This is because long term interplant competition does not only vary with plant population densities but also between varieties of cocoa plants [10]. It has also been reported that short or dwarf cocoa genotypes with superior performance will be more sustainable for adoption under HDP cocoa production [4]. However, farmers need basic knowledge of research for good crop management with appropriate techniques for pruning and thinning of unwanted cocoa stands for better productivity of plants [3]. Consequently, the productivity and profitability of HDP for a longer period in cocoa plantation will somehow depend on the inherent varietal precocity, vigour, drought tolerance, yield production and disease resistance of individual trees as well as the good agricultural practices adopted by farmers.

\section{Conclusion}

The trial focused on the first 3 years after transplanting which revealed that high planting densities of 2500 ha $^{-1}$ and $4445 \mathrm{ha}^{-1}$ which are $2.0 \times 2.0 \mathrm{~m}$ and $1.5 \times 1.5 \mathrm{~m}$ spacing, respectively would maximize yields before cocoa reaches its climax age in Southwestern region of Nigeria. However, for more sustainable production, while cocoa should be established at $1.5 \times 1.5 \mathrm{~m}$, we recommend that the trees be thinned to $3.0 \times 3.0 \mathrm{~m}$ once the interwoven canopies is becoming counterproductive, depending on the variety of cocoa planted. This system will encourage a rapid ground coverage in the first 3 years of field establishment, reduces weed occurrence, prevents mirid infestation, provides a good ecological base for cocoa development and enables a better economic productivity of land and trees during the period. For TC series cocoa variety which used in the present experiment, thinning of cocoa plants to $3.0 \mathrm{x} 3.0 \mathrm{~m}$ is recommended as the trees reach their climax ages around 10 years after transplanting or once the farmers notice the cocoa canopy formation is becoming clumsy or too interwoven. However, since this study was limited to the first 36 months after transplanting or 3 years after transplanting, there is a need for more comprehensive data for a longer period of time to extrapolate the behaviour of mature cocoa trees under both HDP and LDP.

\section{Compliance with ethical standards}

\section{Acknowledgments}

The Authors thank the Executive Director, Cocoa Research Institute of Nigeria, Ibadan for the opportunity to carry out this research project.

\section{Disclosure of conflict of interest}

The Authors declare that there is no conflict of interest on the publication of this research work.

\section{References}

[1] Agbongiarhuoyi AE, Ayegboyin KO, Ogunlade MO and Orisajo SB. Farmers' use of Banana instead of Plantain as Shade Crop in Cocoa Establishment: A Case of Cross River State, Nigeria. World Rural Observation. 2016; 8(1): 14-22.

[2] Cortes S, Perez A. Influence of high planting densities on yields and bean quality. Ciencia y tecnia en la agricultura. CaféCacaoThé. 1986; 4(2): 29-39.

[3] Dias LAS, Kageyama PY. Comparison between multivariate methods applied for the evaluation of genetic divergence in cacao (Theobroma cacao L.). Brazilian Archives of Biology and Technology. 1988; 41: $199-206$. 
[4] Dias LAS, Santos MM, Santos AO, Almeida CMVC, Cruz CD, Carneiro PCS. Effect of planting density on yield and incidence of witches' broom disease in a young plantation of hybrid cacao trees. Experimental Agriculture. 2000; 36: 501-508.

[5] Gutierrez CH. Agronomic Practices in Columbian Cocoa Plantation. Proceedings of Seventh International Cocoa Research Conference, Douala, Cameroon. 1981; 25-29.

[6] Famaye OA, Adeyemi EA, Olaiya OA. Spacing trials in Cocoa, Kola and Citrus. Proceeding of Fourteenth International Cocoa Research Conference, Accra, Ghana. 13-18 October 2003; 501-504.

[7] Famuwagun IB, Agele So. Effects of Sowing Methods and Plant Population Densities on Root Development of Cacao (Theobroma cacao L.) Seedlings in the Nursery. International Journal of Agricultural Research. 2010; 5: 445-452.

[8] ICCO Portal. Quarterly Bulletin of Cocoa Statistics, Vol. XLV, No. 1. ICCO Cocoa Year 2018/19.

[9] Kowal JML. Effect of spacing on the environment and performance of cacao under Nigeria conditions. Empire Journal of Experimental Agriculture. 1959; 27: 27-34.

[10] Lockwood G, Pang JTY. Yields of cocoa clones in response to planting density in Malaysia. Experimental Agriculture. 1996; 32(1): 41-47.

[11] Maharaj K, Indalsingh T, Ramnath D, Cumberbatch A. High Density Planting of Cacao: The Trinidad and Tobago Experience. Proceedings of International Workshop on Cocoa Breeding for Improved Production Systems. 19-21 October 2003; 171-182.

[12] Mooleedhar V. A review of high density planting of cocoa in Trinidad and Tobago. Seminar Series, Central Experiment Station, Centeno, Trinidad (unpublished). In: Maharaj K, Indalsingh T, Ramnath D and Cumberbatch A. High Density Planting of Cacao: The Trinidad and Tobago Experience. Proceedings of International Workshop on Cocoa Breeding for Improved Production Systems. 2003; 171-182.

[13] Mooleedhar V, Lauckner B. Effects of spacing on yield in improved clones of Theobroma cacao L. Tropical Agriculture, Trinidad. 1990; 67(4): 376-378.

[14] Shripat C. Yield and disease incidence on Trinidad Selected Hybrid (TSH) seedlings: A preliminary report. Proceedings of 13th International Cocoa Research Conference, Cocoa Producers Alliance, London, United Kingdom, Kota Kinabalu, Sabah, Malaysia. October 9-14, 2001; 247-253.

[15] Souza CAS, Dias LAS, Aguilar MAG, Sonegheti S, Oliveira J, Costa JLA. Cacao Yield in Different Planting Densities. Brazilian Archives of Biology and Technology, Curitiba. Nov. /Dec. 2009; 52(6).

[16] Wilson CK. Coffee, Cocoa and Tea: Crop Production Science Horticulture. CABI Publishing, Wallingford. 1999; 320 .

[17] Wintgens JN. Influence of Genetic Factors and Agroclimatic conditions on the quality of Cocoa. Secomd International Congress on Cocoa and Chocolate, Munich. May 1991; 55.

[18] Wood GAR, Lass RA. Cocoa, Fourth Edition, Longman, London, UK. 1985; 620.

\section{Author's Short Biography}

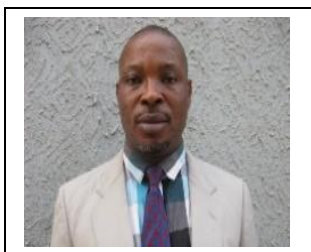

Dr Kayode Olufemi Ayegboyin was born on 21 May 1975 at Ogbomosho, Oyo State, Nigeria. He holds BSc (Hons) in Agriculture and MSc in Crop Science of the University of Ibadan, Ibadan, Nigeria in 1997 and 2005, respectively. He proceeded to the University of Reading, Reading, United Kingdom in 2008 and graduated in 2012 with PhD in Plant Science. He joined the services of Cocoa Research Institute of Nigeria, Ibadan as a Research Officer grade 2 in 2002 and presently awaiting his promotion to Assistant Director with the Institute. He has over 20 research publications on cocoa agronomy, breeding and physiology in many reputable research journals around the world. 